\title{
XVI. On the constitution of acids
}

\section{W.A. Dixon F.I.C. F.C.S.}

To cite this article: W.A. Dixon F.I.C. F.C.S. (1886) XVI. On the constitution of acids, Philosophical Magazine Series 5, 21:129, 127-130, DOI: 10.1080/14786448608627819

To link to this article: http://dx.doi.org/10.1080/14786448608627819

$$
\text { 册 Published online: } 29 \text { Apr } 2009 .
$$

Submit your article to this journal

LII Article views: 2

Q View related articles $\asymp$ 
mixtures of baryta and lime by carbonic acid, found that if the ratio of the two oxides in solution be $\alpha$ and in the precipitate $\beta$, then $\alpha=\kappa \beta$, and that within certain limits of $\alpha$ the value of $\kappa$ was nearly constant. By equation (5) it is seen that if only a very small fraction of the material be precipitated, $\nu=\frac{\epsilon}{\epsilon^{\prime}} \mu$, or $\alpha=\frac{\epsilon}{\epsilon^{\prime}} \beta$; so that the values obtained by Debus for $\kappa$ represent approximately the ratio $\frac{\epsilon}{\epsilon^{\prime}}$ for this particular case.

Chizynski* employed solutions of $\mathrm{MgCl}_{2}$ and $\mathrm{CaCl}_{2}$, to which he added an insufficiency of phosphoric acid for complete precipitation, and to the clear acid solution ammonic hydrate, determining the amounts of $\mathrm{CaO}$ and $\mathrm{MgO}$ in the precipitates with variable quantities of $\mathrm{CaCl}_{2}$ and $\mathrm{MgCl}_{2}$. These experiments, however, do not seem to exhibit fractional precipitation in the true light; for before the addition of the ammonia the phosphoric acid has probably divided itself between the two bases in a determinate manner, and on neutralizing the acid solution the mixed phosphates are precipitated.

XVI, On the Constitution of Acids. By W. A. Dixon, F.1.C., F.C.S., Instructor in Chemistry, Sydney Technical College, N. S. Wales †.

$\mathrm{I}^{\mathrm{N}}$ $\mathrm{N}$ lecturing on Chemistry the question arose in mì mind, Why do some acids form with the alkali metals alkaline hydrogen salts, whilst the similar salts of other acids are acid? And I wish to bring forward the answer to the question which seems to me probable.

We know that in organic compounds there are two cases in which hydrogen is readily replaceable by metals. The first is whon the hydrogen is in combination with oxygen as hydroxyl, as in alcohols, phenols, \&c., and that this hydrogen is more difficult to replace than in the second case, which is when the hydrogen is in combination with two oxygen atoms as oxyhydroxyl. The latter is the mode in which the readily replaceable hydrogen of all the organic acids exists. It seems to me that lydrogen in both these states of combination exists in inorganic acids, and that where both exist in the same acid the hydrogen of the oxyhydroxyl is invariably replaced first. It therefore happens that the principal acid function is in connection with oxyhydroxyl; and it is somewhat doubtful whether an acid which contains hydroxyl only is not more

* Ann. Ch. Pharm. Suppl. vol. iv, 1866.

$\uparrow$ Communicated by Prof. Mills, F.R.S. 
nearly allied to alcohols and phenols than to the true acids. Hydrogen also enters directly into combination; but when it does so the compound generally exhibits acid properties of the feeblest description except when in combination with the extremely chlorous analogues, and when in combination in complex acids it is not replaceable by metals.

I give a few examples from the common acids to explain my meaning; and it will be observed that as a rule the lower, and what is generally to be regarded as the most stable, atomicity of the elements only is required. The exception to this is the halogen group, which must be regarded as entering into oxacid combination as triads. This is scarcely extraordinary, as we know that iodine forms a trichloride, and that therefore it at least must be a triad, or develops triadic functions by reason of its juxtaposition to chlorine. If iodine does so, why may not the other members of this closely allied group of halogens? It appears to me that the metals are more elemental in character, so to speak, and therefore less liable to atomic changes than the non-metals, and that most of the supposed variation in metallic atomicities would disappear if the halogens were triads in certain combinations. If iodine only of the group could assume triatomicity, there is no reason why the monatomic chlorine in iodine trichloride should not be replaceable by monatomic hydrogen; but there is little reason to expect such a substitution if by the combination of these elements triatomic functions were developed in both, so that the compound was not
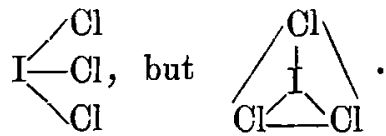

To come to examples, let us first take the phosphorous acids. The orthoacid has probably the composition $\mathrm{P}-\mathrm{OH}$, because the acid itself has strong acid properties ; but these are immediately lost or neutralized by the replacement of the hydrogen of the oxyhydroxyl group by sodium, whilst the replacement of the hydrogen of one hydroxyl group gives a salt having an alkaline reaction.

Phosphorous acid has probably the constitution $\mathrm{P}_{-}^{-} \mathrm{OH}$, and is therefore dibasic, the hydrogen atom being only replaceable by compound radicals resembling itself; but this acid does not form a true acid salt with the alkali metals. 

basic.

Hypophosphorous acid is $\mathrm{P}-\mathrm{OOH}$

Pyrophosphoric acid is probably

, and is therefore mono-

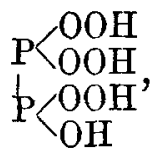

as the dipotassic and disodic salts are acid in reaction, whilst the dipotassic ammonium hydrogen salt is alkaline, showing the feeble acidity of the $\mathrm{OH}$ group; and a tripotassic or trisodic pyrophosphate should also be alkaline.

Orthosilicic acid is usually supposed to be tetrabasic, and could then have only four hydroxyl atoms and no oxyhydroxyl, and should therefore possess scarcely acid properties. The acid obtained by diffusion when perfectly free from chlorine has a very faint acid reaction; but as this solution evaporated in vacuo leaves a residue having the composition $\mathrm{H}_{2} \mathrm{SiO}_{3}$, the acid in solution may be

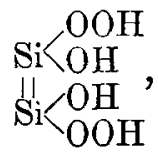

and hence give an acid reaction.

Of the sulphur acids we have sulphuric, $\mathrm{S}<\mathrm{OOH}$, and sulphurous, $\mathrm{S}<\mathrm{OH}$, the first forming acid and the second alkaline hydrogen salts with the alkaline metals. There is also hyposulphurous acid, $\mathrm{s}<_{\mathrm{H}}^{\mathrm{OOH}}$, which should be monobasic, and actually only forms one sodium salt. The substitution of sulphur for oxygen in sulphuric acid renders this sulphuric acid too unstable to form acid salts with the alkali metals. There are some monobasic acids, as nitric, metaphosphoric, and chloric, which may have the same or different constitutions. They may be

or
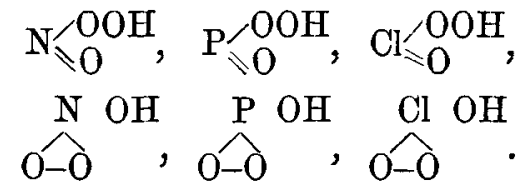

Chloric acid may have the latter constitution; but it seems most probable that nitric acid, from its strongly acid character,

Phil. Mag. S. 5. Vol. 21. No. 129. Feb. $1886 . \quad$ K 
has the former, and also metaphosphoric from analogy and from its formation of dimetaphosphates,<smiles>OO[Pb]1OO[Pb]1O</smiles>

the acid of which is unknown; and more complex compounds of similar type.

Of the lower oxacids of chlorine and nitrogen, chlorous and nitrous, $\mathrm{N}_{\mathrm{O}}<\mathrm{OH}$ and $\mathrm{Cl}_{\mathrm{O}} \mathrm{OH}$, are feeble acids, though forming stable metallic compounds; whilst hyponitrous and hypochlorous may be $\mathrm{N}_{\leqslant} / \mathrm{H}$ and $\mathrm{Cl}_{\leqslant} / \mathrm{H}$, and so are scarcely acids at all. The latter may however contain univalent chlorine, and be $\mathrm{Cl}-\mathrm{OH}$.

XVII. Evidence respecting the Reality of "Transfer-resistance" in Electrolytic Cells. By G. Gore, LL.D., F.R.S.*

TN a paper published in the "Proceedings of the Royal 1 Society,' 1885, no. 236 , vol. xxxviii. p. 209, I have stated that "a species of electric-resistance, distinct from that of polarization and ordinary conduction-resistance, varying greatly in amount in different cases, exists at the surfaces of mutual contact of metals and liquids in electrolytic and voltaic cells," and "this resistance varies largely in amount with different metals in the same solution, and with the same metal in different solutions."

As conduction-resistance is attended by evolution of heat, I took advantage of this fact to search for a difference of temperature produced by "transfer-resistance" at the surfaces of different metals in the same solution, and I now employ the same fact in a somewhat different way to search for difference of heat evolved at the surface of the same metal in different liquids. I use an air-thermometer instead of mercurial ones, and make an experiment like that of Peltier's, but employing a metal and electrolyte instead of two metals.

I took a thin platinum bottle, of a conical shape, of $10.0 \mathrm{~cm}$. total height, $5.0 \mathrm{~cm}$. in diameter at the bottom, and $1.25 \mathrm{~cm}$. diameter at a height of $8.5 \mathrm{~cm}$., at the bottom of the neck.

* Communicated by the Author: read before the Birmingham Philosophical Scciety, January 21st, 1886. 